\title{
Quando o Bom Conhecedor de Almas se Torna Psicólogo Experimentante
}

\author{
Elisabete Marques Jesus de Sousa* \\ Universidade de Lisboa - ULisboa, Lisboa, Portugal \\ ORCID: http://orcid.org/0000-0002-4984-4402
}

\section{RESUMO}

O principal objetivo deste capítulo é analisar e comentar o que o ecléctico pensador dinamarquês Søren Kierkegaard (1813-1855) entende por conhecedor de almas (sjelekyndig), um termo que este filósofo e poeta peculiar faz equivaler a psicólogo na obra Para autoexame, recomendado à época contemporânea. Em concordância com este objectivo, é analisado e comentado o modus operandi do psicólogo experimentante (experimenterende) tal como é assumido por vários dos seus autores narradores, designadamente, Johannes Climacus (em Pós-Escrito), Johannes de silentio (em Temor e Tremor) e Frater Taciturnus (em Estádios no Caminho da Vida). Experimenterende, ou seja, aquele que é definível pela prática da sua capacidade de experimentar, é efetivamente o adjectivo que com maior frequência surge a qualificar o termo "psicólogo". Nesta minha análise, é realçado o papel da imaginação no autor e no leitor e o modo como se associa à faculdade do juízo na interação leitor-texto-autor. É também sublinhado o papel fundamental do poético e do literário em todo este processo.

Palavras-chave: Kierkegaard, psicólogo experimentante, imaginação, recriação poéticoliterári, conhecedor de almas.

\section{When the Good Judge of Souls Becomes an Experimenting Psychologist}

\begin{abstract}
The main objective of this chapter is to analyze and comment on what the eclectic Danish thinker Søren Kierkegaard (1813-1855) understands by a good judge of souls (sjelekyndig), a term that this peculiar philosopher and poet makes equivalent to psychologist in the work For Self-Examination. In agreement with this objective, the modus operandi of the experimenting psychologist (experimenterende) is analyzed and commented on as it is carried out by several of its narrating authors, namely, Johannes Climacus (in Postscript), Johannes de silentio (in Fear and Tremor) and Frater Taciturnus (in Stadiums on the Way of Life). Experimenterende (that is to say, the one that can be defined by putting in practice his ability to experiment) is indeed the adjective that is most frequently used to qualify the term "psychologist". Special emphasis is given to the role of imagination in the author and in the reader and the way imagination joins the faculty of judgment in the interaction between reader-text-author. Special attention is given to the role of the poetic and the literary within the whole process.
\end{abstract}

Keywords: Kierkegaard, experimenting psychologist, imagination, poetic and literary recreation, good judge of souls (sjelekyndig). 


\section{Cuando el Conocedor del Alma se Convierte en Psicólogo Experimental}

\section{RESUMEN}

El objetivo principal de este capítulo es analizar y comentar lo que el ecléctico pensador danés Søren Kierkegaard (1813-1855) entiende por conocedor del alma (sjelekyndig), un término que este peculiar filósofo y poeta equipara a un psicólogo en la obra La Enfermedad Mortal. De acuerdo con este objetivo, se analiza y comenta el modus operandi del psicólogo experimental (experimenterende) como lo asumen varios de sus autores narradores, a saber, Johannes Climacus (en Pós-Escrito), Johannes de silentio (en Temor y Temblor) y Frater Taciturnus (en Estadios en el Camino de la Vida). Experimenterende, es decir, uno que se puede definir a través de la práctica de su habilidad para experimentar, es efectivamente el adjetivo que con mayor frecuencia parece calificar el término "psicólogo". En mi análisis, se destaca el papel de la imaginación en el autor y el lector y la forma en que se asocia con la facultad de juicio en la interacción lector-texto-autor. También se subraya el papel fundamental de lo poético y lo literario en todo este proceso.

Palabras clave: Kierkegaard, psicólogo experimental, imaginación, recreación poéticoliteraria, conocedor del alma.

É sabido que os autores kierkegaardianos, enquanto narradores omniscientes das obras que assinam, exibem ostensivamente uma vertente de psicólogos, qualidade que apesar de descontinuidades e até de contrastes acentuados entre esses autores confere às respetivas narrativas um registo hermenêutico que justifica uma leitura à luz da psicologia. São de todos os leitores bem familiares as tantas vezes exaustivas (e repetitivas) caracterizações anímicas e descrições comportamentais de personagens literárias, históricas e mitológicas, acompanhadas de indagações justificativas dos seus atos ou remorsos e angústias, também frequentemente seguidas de um convite ao leitor, e à sua imaginação, para se juntar ao autor na recriação dos contextos existenciais dessas mesmas personagens; e o autor, a partir desses contextos existenciais recriados, acaba habitualmente por propor novas conclusões de índole diversa às que haviam definido uma dada personagem até então - é, entre outros, o caso de Antígona no capítulo do trágico na primeira parte de Ou-Ou. Um Fragmento de Vida (Kierkegaard, 1843/2013a).

O próprio Kierkegaard (1851/2009a), em Para auto-exame, recomendado à época contemporânea, afirma que é reconhecido entre os seus contemporâneos como alguém que conhece bem almas, fazendo equivaler o autoexplicativo termo sjelekyndig a psicólogo: "Talvez eu até desfrute de algum reconhecimento entre os meus contemporâneos como conhecedor de almas (psicólogo) (Kierkegaard, 1851/2009a, p. 48). Anteriormente, em Doença para a Morte (Kierkegaard, 1849/2006), sjelekyndig denotava mais claramente o 
objeto de estudo e de especialização, ao ser implicitamente posto em paralelo com o médico este estuda e conhece, e pode curar os males do corpo, ao passo que o conhecedor de almas, estuda e conhece, e pode curar os males da alma:

Pois um médico não tem simplesmente de prescrever remédios, tem acima de tudo de conhecer a doença e, portanto, tem acima de tudo de reconhecer se o presumível paciente está realmente doente, ou se o indivíduo presumivelmente saudável não estará talvez realmente doente. Também assim se passa com o conhecedor de almas em relação ao desespero. Ele sabe o que é o desespero, conhece-o e por isso não se contenta com a afirmação de um indivíduo que diz não estar desesperado ou que diz estar [desesperado]. (tradução minha; Kierkegaard, 2009a, p. 139-40)

Nos escritos de Kierkegaard, nem sempre a separação de tarefas entre médico e psicólogo parece ser tão distinta, o que é sem dúvida ainda um vestígio de a medicina, desde os tempos de Hipócrates, ter como campo de ação o homem no seu todo. Disso faz prova o fato de a teoria dos humores provir da Antiguidade e ter continuado a ser estudada, divulgada e aplicada até meados do século dezoito. Assim, no discurso Por Ocasião de Uma Confissão (1845), Kierkegaard atribui ao médico ou ao conhecedor de almas a tarefa de descrever o sofrimento e as suas mutações: "Ah, Talvez o teu sofrimento permanecesse inalterado durante anos; e, se houvesse alteração, então, tal passa deveras a ser matéria para o médico ou o conhecedor de almas descreverem" (Kierkegaard, 2004, p. 244). Possivelmente, descrevê-loiam de maneira diferente, mas partilhando o mesmo objeto de estudo, pelo que, para caracterizar cabalmente o sofrimento, será necessário contar com a descrição de ambos, a do médico e a do conhecedor de almas.

Quanto ao termo psicólogo, surge algumas vezes classificado como experimentante ou experimentador (usado na tradução de Álvaro L. M. Valls), ou seja, associando a prática da psicologia ao conceito de "experimentação" que surge como um método e não como uma mera tentativa de fazer algo. Johannes Climacus apresenta-se, aliás, como psicólogo experimentante humorístico (Kierkegaard, 2016, p. 342) e menciona ainda outra vez esta qualidade como determinante para poder analisar o tipo de loucura de Dom Quixote (Kierkegaard, 2013b, p. 206).

Mas é na carta conclusiva do capítulo “Culpado?-Não Culpado?”, em Estádios no Caminho da Vida (1845), que encontramos uma descrição mais clara do que se pode entender por psicólogo experimentante. Frater Taciturnius, antes de desenvolver a sua tese sobre o 
perdão do pecado, identifica-se nessa qualidade, ao mesmo tempo que se distancia de quadros sinóticos, como os comentados sobre números relativos a suicídios na extensa nota sobre Cartas de Paris [Briefe aus Paris (1834)] de Ludwig Börne (1786-1837), na qual Börne, curiosamente, é classificado como diretor espiritual, literalmente o cuidador de almas (sjelesфrger). Afirma Taciturnus:

Um psicólogo experimentante não fica servido com quadros sinóticos; mas também não precisa, pois, de um tão grande afluxo de indivíduos.// Uma vez mais, voltei a colocar de modo experimental um problema do foro do religioso: o perdão do pecado. (Kierkegaard, 1845/1999, p. 442)

Logo na sua nota prévia ao mencionado capítulo, Taciturnus mencionava o diário de Quidam como obra de um pobre psicólogo sem grandes ambições de ser bem compreendido, como que justificando a forma literária diarística como um modo de seduzir o leitor. As considerações seguintes são particularmente interessantes para perceber, por um lado, o que nos escritos de Kierkegaard se entende por experimento psicológico e, por outro, para perspetivar a necessidade de recriar personagens, de imaginar contextos existenciais, numa palavra, de dar livre curso à criação poética e à ficção, não como um mero artifício literário, mas antes como parte essencial da experimentação, com o intuito de obter um duplo efeito: cativar o leitor para o objeto de estudo, envolvendo a imaginação deste no constructo exposto, para que dessa maneira se possa potenciar o conhecimento adquirido a partir da observação desse objeto de estudo, procurando estabilizar um contexto existencial que seja emblemático para ilustrar um dado conceito ou categoria ou estado de alma. Eis o excerto em questão:

Se alguém não se quiser sentir assim obrigado a fazer alguma coisa, então talvez se pudesse considerar mir nichts e dir nichts [sem delongas] que um coitado de um psicólogo que apenas ouse poder contar com pouca simpatia por experimentos psicológicos e constructos irreais fez um ensaio para cativar uma ou outra pessoa, dando-lhe um toque de novela. Pois um desenho propriamente psicológico que não pergunte se semelhante pessoa viveu talvez diga menos à nossa época, na qual a própria poesia agarrou o expediente de querer produzir o efeito da realidade. Alguma psicologia, alguma observação das assim chamadas pessoas reais, ainda se aceita, mas quando essa ciência ou arte segue o seu gosto, quando põe de lado as expressões imperfeitas dos estados de alma que a realidade oferece, quando se esquiva para só 
consigo mesma criar uma individualidade a partir do seu próprio conhecimento, e encontra nessa individualidade um objeto para sua observação, então, há muito quem se canse. Na realidade efetiva, designadamente, as paixões, os estados de alma, etc. só se encontram até certo grau. Também isso regozija a psicologia, mas há simultaneamente um outro regozijo que se retira de ver a paixão levada ao seu extremo limite (Kierkegaard, 1845/1999, p. 178-179)

Experimentação implica então enveredar por campos tão exploratórios quanto combinatórios fazendo aliar a psicologia ao exercício da imaginação que se manifesta através do exercício de formas de arte, designadamente a poético-literária, por parte do autor, e através de uma nova forma de leitura, também ela experimental para o leitor, cuja imaginação e capacidade de juízo estético se aliam, tornando-se equitativamente decisivas para que se verifique harmonia entre logos, ethos e pathos.

É também perfeitamente coerente e consistente que um dos traços de carácter comum a todos os autores resida no fato de cada um deles fazer deste tipo de experimentação psicológica e psicologista uma aliada de um outro domínio, que tanto pode ser mais de pendor estético, como de maior pendor ético, ou marcadamente religioso, e, por conseguinte, requerer imaginação e capacidade de juízo estético por parte do leitor, e exercício da fantasia, a imaginação criadora dos românticos, por parte do autor. Por exemplo, Anti-Climacus, o fabuloso autor de Doença para a Morte, assina a obra com o elucidativo subtítulo Uma Exposição Cristã e Psicológica para Edificação e Ressurreição.

É desta forma que, com maior ou menor incidência, os autores kierkegaardianos põem em prática, descrevem ou exemplificam modalidades diversas de psicologia, enquanto campo do saber inédito para autor e para leitor, acolhendo até práticas e perspetivas cujos princípios podem entrechocar-se. Kierkegaard nunca esconde o jogo que pretende jogar. Com efeito, se atentarmos nos propósitos que habitualmente prefácios ou introduções de capítulos encerram, ou tão-somente nos títulos, à semelhança do último exemplo, obtemos pistas esclarecedoras sobre as diferentes vias de experimentação psicológica. Entre os autores kierkegaardianos, há os que se apresentam de imediato na qualidade de psicólogos e bons conhecedores da matéria. É o caso de Vigilius Haufniensis que escreve um tratado sobre a angústia desde logo rotulado como exploração psicológica e simultaneamente teológica. Constantin Constantius não lhe fica atrás e anuncia-se como autor de um ensaio de psicologia experimental. Anteriormente, já se constatara que "Diário do Sedutor" é protagonizado por alguém que faz equivaler sedução à manipulação psicológica da seduzida. A par destes casos explícitos e incontornáveis, 
encontramos outros mais subtis em textos da mais profunda introspeção. Refiro-me ao já mencionado diário de Quidam, em Estádios no Caminho da Vida, mas também a outros escritos que proclamam a necessidade de autoanálise tal como Julguem por Vós mesmos!. E não são menos significativos os casos de introspeção e de autoavaliação da condição de autor, tão óbvios nos diários e em O Ponto de Vista Para a Minha Atividade de Autor.

Enquanto narradores omniscientes, os autores kierkegaardianos dominam plenamente a matéria exposta ao leitor. Por outras palavras, é deles a 'verdade' e a 'verosimilhança' do texto, são eles quem ditam as regras da escrita e são eles os responsáveis por toda a conceção narrativa e/ou retórica. É frequente ver-se a narração na primeira pessoa fazer-se acompanhar por um intenso dialogismo, ou seja, a narração na primeira pessoa é entrecortada por falas ou por parágrafos expositivos que são atribuídos a terceiros, quando os narradores criam personagens intervenientes na matéria ou ação em causa. Estas personagens, por sua vez, geram novas visões extrospetivas ou introspetivas que expõem novas verdades e novas verosimilhanças, frequentemente com alguma fricção ou mesmo colisão, obviamente deliberadamente manipuladora do leitor.

O dialogismo pode ocorrer dentro do próprio eu. É o caso do capítulo "Diapsalmata" na Parte I de $\mathrm{Ou}$-Ou, com a alternância de explosões do eu, eufóricas ou disfóricas, prototeóricas ou aforísticas, com comentários sobre o contexto existencial desse eu, igualmente eufóricos ou disfóricos, prototeóricos ou aforísticos, assistindo o leitor ao desfilar de situações em que o movimento de introspeção é acompanhado pendularmente por um movimento de extrospeção. A organização diegética marcada por forte dialogismo traz por arrasto o surgimento de múltiplos ângulos de observação do si mesmo e do outro. E é a especificidade do dialogismo textual que define o perfil identitário do texto em questão na relação estreita do autor com a matéria exposta. Por exemplo, a forma diarística e a inserção de cartas de Cordelia confere ao carácter psicologista de "Diário do Sedutor" uma vertente inter-relacional bem mais visível do que a oferecida pelo diário de Quidam em Estádios no Caminho da Vida. Por seu turno, as cartas do Juiz na Parte II de $\mathrm{Ou}$-Ou, ao ficar sem resposta verbal ou comportamental vinda da parte do destinatário (supostamente $\mathrm{A}$, o autor dos papéis da Parte I de $\mathrm{Ou}-\mathrm{Ou}$ ), acabam por ser lidas não como aviso ou conselho de um amigo a outro amigo, mas como uma exposição do que o Juiz entende ser o ético na existência do indivíduo singular.

A multiplicidade de focalizações sobre um mesmo assunto, gerada pelo dialogismo, é especialmente visível em In Vino Veritas, dado que há autores que reaparecem na qualidade de personagens a par de outras personagens que pela primeira vez entram em cena. A unir o 
conjunto de comentários apresentados neste capítulo de Estádios no Caminho da Vida em torno da natureza e do carácter específico da mulher está o intento de produzir uma panorâmica multifacetada do ponto de vista masculino sobre o que poderá ser o amor e a mulher tidos como objeto de amor do homem. Interessantemente, este painel de comentadores, a meu ver, fica aquém do retrato psicológico da mulher seduzida que já havia sido alvo de tratamento marcadamente literário no capítulo "Silhuetas" e em "Diário do Sedutor" na Parte I de Ou-Ou. Um Fragmento de Vida. Ora, este fato corrobora o que atrás comentámos sobre o passo de Taciturnus e nos deixa mais clara a frase conclusiva do excerto: “Também isso regozija a psicologia, mas há simultaneamente um outro regozijo que se retira de ver a paixão levada ao seu extremo limite."

Por conseguinte, é por demais evidente nos textos do nosso filósofo que a construção de personagens que manifestam uma rica profundidade psicológica extravasa a mera (re)criação literária. A galeria de personagens que formam a mitologia de Kierkegaard não é constituída por deuses ou figuras deificadas e, por conseguinte, intocáveis e imutáveis na sua descrição, mas antes por personagens que são sujeitas a experimentação psicológica, dando então lugar a seres que realmente se humanizam, caracterizados por um intenso pathos, de molde a serem capazes de manifestar os seus sentimentos, de ter arrependimento, de exprimir emoções e de suscitar uma reação por parte do leitor. Todo esse cortejo de figuras inspiradas em protagonistas de textos da antiguidade grega e latina, da bíblia, da história, da literatura da tradição ocidental, percorre transversalmente a produção kierkegaardiana. E são tantos e tão assíduos frequentadores de todo o tipo de obras (até nos discursos edificantes de 1843 a 1850) que se torna difícil destacar um exemplo. Recordemos simplesmente as imensas personagens que povoam em particular Ou-Ou. Um Fragmento de Vida. Primeira Parte e o "Problema III" de Temor e Tremor e apercebermo-nos até que ponto Don Juan, Nero, Antígona, Marguerite, o Judeu Errante, o Tritão, a Noiva de Delfos, Diana, Antígona, e tantas outras figuras, ilustram uma nova existência fora dos contextos originais, quando surgem reconfiguradas através de uma apropriação e recriação poética do mais fino recorte que pôde e soube revestilas de uma personalidade própria resultante de uma experimentação poético-literário ao serviço da demonstração dos casos extremos que são inobserváveis ou muito difíceis de encontrar na realidade que nos rodeia. Surgem então dotados de uma personalidade marcadamente expressiva e única, que visa apresentar e simultaneamente representar os conceitos e/ou categorias contidos nos textos kierkegaardianos onde agora habitam. E, num nível ainda mais elaborado, encontramos também escritos cujo carácter edificante depende da reflexão decorrente da recriação de um caso de observação direta de um terceiro que é depois 
comentado para dele se extrair um preceito moral, por vezes uma norma de boa regra de vida, para edificação de dois outros terceiros, a começar pelo leitor e pelo autor enquanto leitor de si mesmo. Cabem neste caso, em particular, os magníficos discursos publicados entre 1849 e 1850 - O Lírio no Campo e a Ave no Céu. Três Discursos Piedosos e O Supremo Sacerdote, O Cobrador de Impostos e A Mulher que era Pecadora. Três Discursos para a Comunhão às Sextas-Feiras.

Assim, os autores distinguem-se não apenas pelo estilo, pela estruturação capitular ou pelo modelo organizacional das suas obras, ou pelos tópicos, categorias ou disposições que escolhem para assunto, sejam eles de carácter teológico, filosófico, sociológico, literário ou psicológico, mas também pela arte combinatória que marca retoricamente os textos, designadamente o ethos do narrador, que se apresenta enquanto protopsicólogo (e tantas vezes enquanto proto-antropólogo), deixando para trás o bom conhecedor de almas e abrindo caminho ao perfil de psicólogo, tal como comummente tomamos o termo. Diga-se, aliás, que a profundidade psicológica desses autores e/ou narradores também se revela na sua própria multiplicidade de transições e de disposições que espelham aquelas que vão sendo construídas a fim de apresentar os temas centrais de cada obra, confluindo então nessa afinação que emana da tríade texto-leitor-autor. Acresce ainda que o grau de profundidade no desenvolvimento desses temas é obtido através de um efeito de aceleração ou de desaceleração do pensamento (e respetiva exposição), que ora é centrípeto, ora é centrífugo, ou seja, ora se projeta de fora olhando para dentro, ora se projeta de dentro olhando para fora. Esta é aliás uma maneira de materializar na escrita a categoria de salto, o que por si só prova que a categoria de salto detém um campo de aplicação que não se restringe à fé e ao domínio religioso.

Antes de passar a apresentar mais alguns exemplos, recorrendo essencialmente a Johannes de silentio, cabe-me fazer duas breves observações que permitem lembrar o reconhecido contributo dos escritos de Kierkegaard para a investigação em psicologia. Em primeiro lugar, uma nota sobre a obra Kierkegaards Psykologi de Kresten Nordentoft de 1972 e, em segundo, outra sobre a generalidade da receção no campo da psicologia e da psiquiatria. A relevância do pensamento e da reflexão de Kierkegaard sobre o psiquismo, sobre o comportamento e sobre o inter-relacionamento humano mereceu grande interesse e decorrente pesquisa mesmo antes da obra magistral e monumental de Nordentoft. Tal como este autor indica na sua tradução, o primeiro grande estudo publicado em Copenhaga data de 1933, da autoria de Hjalmar Herweg, com o elucidativo título S.K., En psykiatrisk-psykologisk Studie, e como também sabemos, por exemplo, a prática e as teorias do psiquiatra Ludwig Binswanger, 
pioneiro na área da psicologia existencial, estão profundamente marcadas pelo pensamento do dinamarquês já a partir das décadas de vinte e trinta do século passado. Isso significa que esta recepção na psicologia e na psiquiatria, tendo lugar quase um século depois da publicação das obras de Kierkegaard, é contemporânea da primeira grande receção da obra do dinamarquês por parte de filósofos alemães, entre eles obviamente Martin Heidegger, e por parte de vultos enormes da literatura alemã como Thomas Mann. Poucos anos depois, o existencialismo, em certa medida, deslocou a dualidade desta receção que dava primazia à psicologia e à filosofia para uma quase rivalidade entre dois tipos de hermenêutica do texto kierkegaardiano - a teológica e a filosófica. Acresce que a receção no campo da psiquiatria e da psicologia viu-se igualmente relegada para segundo plano devido ao impacto do pensamento de Sigmund Freud. E, como é sabido, as vagas de discípulos e/ou de dissidentes de Freud nem sempre farão justiça a quanto Freud ficou a dever a Kierkegaard, e só bastante mais tarde voltarão a Kierkegaard - talvez o exemplo mais conhecido seja o de Jacques Derrida, por exemplo, em Donner la mort.

Kierkegaards Psicologi de Kresten Nordentoft surge não como um manifesto em prol do ressurgimento de Kierkegaard como filósofo e protopsicólogo determinante para dois campos científicos que estavam plenamente consolidados no início da década de setenta do século vinte, mas antes como a prova cientificamente demonstrada de que na génese do pensamento freudiano e nas categorias por Freud criadas (e que de um ou de outro modo, por seguimento, ou agindo a contrario, constantes no processo de apropriação pelos que vieram depois do fundador da psicanálise) se encontra a reflexão de Kierkegaard sobre o que move a mente humana e determina o agir do homem - designadamente, a angústia e o desespero - e sobre as implicações e relações da angústia e do desespero com mecanismos de culpabilização, graus de consciência, o papel fundador do desejo, etc.

Não é este o lugar para fazer uma exposição detalhada das quase quatrocentas páginas de Kierkegaards Psicologi. Mas recomendo vivamente uma leitura quanto mais não seja do plano perfeitamente delineado que preside à estrutura da obra. $\mathrm{Na}$ introdução, Nordentoft afirma que em Kierkegaard a psicologia nunca anda só e nem sequer constitui o seu foco principal - não pode ser separada de outras matérias. Diz Nordentoft: "Por isso, uma exposição que venha a fazer justiça à psicologia de Kierkegaard tem também de lidar no seu caminho com matérias que não são psicológicas em sentido estrito, mas sim literárias, éticas, sociais, filosóficas e teológicas." (Nordentoft, 1972/2009, p. 17) E Nordentoft afirma que a visão cristã de Kierkegaard contém "dimensões e pontos de vista que a teologia raramente possui." (Nordentoft, 1972/2009) Pode pois dizer-se com inteira justeza que Kierkegaard é o 
grande criador de textos que geram corredores de comunicação não só entre o estético, o ético e o religioso, como teorizado por Frater Taciturnus, mas entre domínios do saber e da arte entre a poesia e a filosofia, entre a música e a subjetividade, entre a psicologia então emergente e a literatura, entre a teologia e a filosofia. E é neste deliberado e permanente cruzamento de semelhantes filões de pensamento que Kierkegaard se manifesta como pensador cujos múltiplos autores se tornam casos únicos de pensamento e de praxis tidos tão experimentantes quanto os novos campos que exploram são passíveis de experimentação. Lembremos que fermentação é uma palavra muito cara a Kierkegaard - e tudo o que fermenta não volta à forma original, passa a ser algo diferente.

Comento agora o caso de Johannes de silentio na sua figura de psicólogo dominado pela experimentação. Ele é o grande "afinador", o hábil mestre em estruturar em capítulos e correspondentes tipos de narrativa transformando-os nos já mencionados corredores de comunicação entre domínios do saber e da arte e contextos existenciais do indivíduo singular. Johannes de silentio ilustra bem como a focalização do narrador obtida através de uma lente psicológica lhe permite escrever um texto no qual coabitam as esferas do estético, do ético e do religioso. Como já tenho sublinhado ao analisar Temor e Tremor, as palavras com que Johannes de silentio no Prefácio se demarca do hegelianismo dinamarquês, podem ser usadas para descrever o modo como cada uma das obras de Kierkegaard atua sobre o leitor. É muito comum que o leitor se sinta ora "por fora", ora "por dentro" do pensamento de cada um desses autores, instanciado na esfera do estético, ou na do ético, ou do religioso ou ainda na sua interseção, criando-se desta maneira um ponto de vista através do qual se entende um tópico, uma categoria ou um conceito, cujo contexto pode ou não situar-se no mesmo posicionamento de cada um desses autores e, obviamente, de cada um dos leitores. O mesmo parece ter aliás acontecido com Kierkegaard, pois há momentos em Temor e Tremor que nos fazem intuir os motivos pelos quais o filósofo pensou no nome do monge sírio Simão Estilita como pseudónimo-autor e em Movimentos e Posições para título inicial. Diga-se, aliás que estes movimentos e posições são tanto de corpo como de espírito. Johannes de silentio parece estar posicionado no topo de uma plataforma, observando o que a seus pés acontece, à espera de captar o momento certo que fixe intemporalmente aquilo que ele quer que a nossa memória retenha para mais tarde recordar, sem que ele perca o equilíbrio do corpo, do pensamento e das palavras. Em Temor e Tremor, todas as personagens se deslocam e nessas deslocações, na maioria das vezes conflui o que é físico e motor, o que é anímico e do foro cognitivo, o que é participado ou vivido num contexto natural ou ambiental ou simplesmente em pensamento tudo isto é descrito com minúcia e rigor, mas com a preocupação de captar nessas 
movimentações o "instante da declinação". Se na bússola, a declinação magnética é o desvio da agulha em relação ao norte geográfico, em Temor e Tremor, o instante da declinação é aquele que marca o início de um salto cognitivo, emocional ou religioso: é o instante em que a paixão atinge o ponto extremo - o sentimento oculto deflagra, a fuga até então evitada precipita-se, a vida que parecia perdida redime-se, o riso ou o choro reprimidos irrompem. Esses instantes de declinação permitem assim visualizar uma paixão que ainda não fora verbalizada, que permanecera latente ou reprimida. A sucessão de exemplo que a seguir aponto ilustra bem como ao movimento físico corresponde uma movimentação anímica. Lemos, assim, como Isaac adivinha o conflito terrível de Abraão cuja olhar deixa transparecer a agitação interior (Kierkegaard, 2009b, p. 58); ao vermos na mão de Abraão a faca que pode determinar o destino de Isaac, este e o leitor entendem a tragicidade dessa agitação (Kierkegaard, 2009b, p. 73); no capítulo "Disposição", os olhares de Sara e de Abraão ficam tão perdidos nessas variações da Aquedah quanto os passos perdidos nas idas e vindas na sua infrutífera deambulação a caminho do Monte Moriá, dando-nos a perceber que os passos perdidos traduzem fisicamente as inquietações que deixaram o patriarca de espírito perdido. Mais adiante, seguimos os encontros e desencontros de palavras e de gestos entre o pregador e o seu diligente e cumpridor ouvinte até que o pregador surge a nossos olhos como um querubim às portas do Paraíso, vendo nós assim que um é o outro (Kierkegaard, 2009b, p. 8182); seguimos o passo enérgico do cobrador de impostos e o seu carácter firme corporizados numa figura sem fissuras, e entendemos que interior e exterior nele se fundem (Kierkegaard, 2009b, p. 93-94). Seguimos a argumentação dialética do pensamento de Johannes sem hesitações, pois antes de lermos os três capítulos nomeados "Problemas", já sabíamos que podemos executar pelo menos um movimento do "cavaleiro da fé" - os pensamentos voam e regressam como pombas amestradas que também afastamos para nos deixar ver adiante (Kierkegaard, 2009b, p. 98-99). Apercebemo-nos de que cada inclinação de cabeça de Agnete, cada mergulho do Tritão, cada passo da noiva de Delfos, cada gesto das suas acompanhantes, são variações da chegada do momento em que os amantes se separam; apercebemo-nos de que Ifigénia enredada nos joelhos de Agamémnon, o choro da filha de Jefté, o rosto expectante e crispado de Raguel, mãe de Sara, representam instantes em que "a dúvida irrompe de forma bravia e incontrolável" (Kierkegaard, 2009b, p. 176); apercebemonos de que a agilidade da esgrima dialéctica com Hegel e Kant se tornam possíveis pelo trabalho poético de quem é capaz de trazer de volta as nuvens do esquecimento (Kierkegaard, 2009b, p. 66) com a mesma arte com que o bailarino se eleva e se fixa no salto e parece aí permanecer (Kierkegaard, 2009b, 97). Este carrossel de intensas movimentações anímicas e 
físicas, cognitivas e cinéticas, contrasta com a anunciada ausência de movimento do "cavaleiro da fé", uma ausência de movimento que nem por isso deixa de ser simultaneamente física e anímica: ele pára na fé, não vai para além da fé, não porque o crente seja alguém que não se move ou que não age, mas porque consegue assim refletir na existência de crente e ganhar uma visão interiror que de outra maneira não encontraria. Para o Abraão de Johannes, não ir para além de fé é ficar a viver na fé e ser feliz com ela, é encontrar o "sublime no pedestre", é existir acreditando.

Nos episódios de Temor e Tremor, a representação do amor como força vital encontrase em situações que recriam contextos existenciais para todo o tipo de personagens, levandoas a apresentarem, a viverem, esse sentimento de uma maneira extremada, mostrando-o em sequências do que poderíamos chamar quadros vivos. Não só estas personagens estão determinadas por esse sentimento - seja ele paternal, filial, fraternal, erótico, para com a divindade, para com a polis, ou a filosofia, como, na maioria dos casos, a ultrapassagem desse amor implica não só o reconhecimento de que o amor se perdeu (e por isso, só pode existir na recordação do modo como foi vivido e na tentativa de repetição de idênticas vivências), como também a quase inevitabilidade da morte de uma das partes ou o seu desaparecimento enquanto destiinatário do amor de um outro. Pensemos nos elos existentes entre Abraão e Isaac, entre Deus e Abraão, ou entre Isaac e Deus; no que une e desune Agamémnon e Ifigénia, Jefté e a filha, Brutus e os filhos, e no que une e desune Micenas e Agamémnon, Israel e Jefté, Roma e Brutus. Tudo contribui para mostrar que na relação por eles vivida ou vence o sentimento nascido dos laços naturais, ou vence o sentimento nascido dos laços contraídos para com a comunidade, quer esses laços possuam uma dimensão nitidamente religiosa ou acentuadamente cívica, i.e. ou o amor pode ser vivido ou sucumbe. Por seu turno, os pares de apixonados a que Johannes recorre maioritariamente no "Problema III" acabam seoparados por condicionalismos simultaneamente casuais e acidentais. A noiva de Delfos é abandonada pelo noivo que receia o cumprimento do oráculo e será ele próprio alvo da vingança por parte da família da noiva; Axel e Valborg, e Agnete e o Tritão, representam a paixão correspondida da maneira certa, mas nas circunstâncias erradas. E o amor à sabedoria também não tem melhor sorte. Fausto e Sócrates veem a sua demanda pelo conhecimento terminar com a sua própria morte.

O autossacrifício é apresentado como uma parte fulcral para outros tipos de amor através da exposição de contextos existenciais. Entre todos os casos apresentados em Temor e Tremor, o episódio de Tobias, também no "Problema III", será talvez aquele em que se concentra um maior número de personagens, com variadas ligações de afeto entre si, 
evidenciando em simultâneo um grau de autossacrifício justificado não apenas do ponto de vista religioso. Com efeito, para que possa um dia viver a consumação de um casamento, Sara abdicou de querer ser feliz porque na sua vida real sempre foi infeliz, e todos os parentes e criados de Sara e de Tobias estão envolvidos nessa abdicação.

Termino retomando outro passo da introdução de Nordentoft à tradução americana da sua obra. Nordentoft congratula-se pelo facto de nesse tempo, já a psicologia existencial ter feito uso do pensamento de Kierkegaard para perspetivar criticamente o que ele designa como "conceções do homem mantidas pela psicanálise e pela psicologia experimental", as quais, nas suas palavras, "ignoram o carácter concreto e histórico da existência" (Nordentoft, 1972/2009, p. 19-20). Possa o indelével carácter de psicólogo experimentante que transborda de cada um dos autores-pseudónimos ter contribuído para que demonstrar que em Kierkegaard jamais se ignora o carácter concreto e histórico da existência de cada um de nós, pois ele é sempre reinventado, e que a imaginação é o fermento que lhe leveda o pensamento.

\section{Referências}

Kierkegaard, S. A. (1997). Enten - Eller, Første del. Sфren Kierkegaards Skrifter (Vol. 2). Copenhaga: G.E.C. Gads Forlag. (Obra original publicada em 1843)

Kierkegaard, S. A. (1999). Stadier paa Livets Vei: Søren Kierkegaards Skrifter (Vol. 6). Copenhaga: G.E.C. Gads Forlag. (Obra original publicada em 1845)

Kierkegaard, S. A. (2002). Afsluttende uvidenskabelig Efterskrift: Sфren Kierkegaards Skrifter

(Vol. 7). Copenhaga: G.E.C. Gads Forlag. (Obra original publicada em 1846)

Kierkegaard, S. A. (2004). En Literair Anmeldelse: Opbyggelige Taler i forskjellig Aand. Søren Kierkegaards Skrifter (Vol. 8). Copenhaga: G.E.C. Gads Forlag. (Obra original publicada em 1846)

Kierkegaard, S. A. (2006). Lilien paa Marken og Fuglen under Himlen. Tvende ethisk religieuse Smaa-Afhandlinger: Sygdommen til Dфden: "Yppersteprasten" "Tolderen” - "Synderinden”: Sфren Kierkegaards Skrifter (Vol. 11). Copenhaga: G.E.C. Gads Forlag. (Obra original publicada em 1849)

Kierkegaard, S. A. (2009a). Om min Forfatter-Virksomhed, Til Selvprøvelse Samtiden anbefalet, Dette skal siges; saa vare det da sagt, Hvad Christus dømmer om officiel Christendom, Guds Uforanderlighed og Øieblikket nr. 1-10. Sфren Kierkegaards Skrifter (Vol. 13). Copenhaga: G.E.C. Gads Forlag. (Obra original publicada em 1851) 
Kierkegaard, S. A. (2009b). Temor e Tremor. Lisboa: Relógio d'Água. (Obra original publicada em 1843)

Kierkegaard, S. A. (2013a). Ou-Ou: Um Fragmento de Vida (Vol. 1). Lisboa: Relógio d'Água. (Obra original publicada em 1843)

Kierkegaard, S. A. (2013b). Pós-escrito às Migalhas Filosóficas (Vol. 1, A. L. M. Valls \& M. M. Almeida, Trads.). Petrópolis, RJ: Vozes.

Kierkegaard, S. A. (2016). Pós-escrito às Migalhas Filosóficas (Vol. 2, A. L. M. Valls \& M. M. Almeida, Trads.). Petrópolis, RJ: Vozes.

Nordentoft, K. (2009). Kierkegaard's Psychology: Kierkegaard Classic Studies. Eugene, Oregon: Wipf and Stock. (Obra original publicada em 1972)

\section{Endereço para correspondência}

\section{Elisabete Marques Jesus de Sousa}

Centro de Filosofia da Universidade de Lisboa - Faculdade de Letras

Alameda da Universidade, 1600-214, Lisboa, Portugal

Endereço eletrônico: elisabetemdesousa@gmail.com

Recebido em: 12/06/2020

Aceito em: 11/08/2020

\section{Notas}

* Pesquisadora do Centro de Filosofia da Universidade de Lisboa. Doutorado (2006) em Teoria da Literatura. Pós-doutorado (2008-15) em Filosofia. Traduz Kierkegaard.

Este artigo de revista Estudos e Pesquisas em Psicologia é licenciado sob uma Licença Creative Commons Atribuição-Não Comercial 3.0 Não Adaptada. 